\title{
CRÓNICA
}

\section{Trayectorias: música entre Latinoamérica y Europa 1970-2000 Tercera Conferencia Internacional de la Red "Trayectorias"}

Universidad Alberto Hurtado, Santiago de Chile, 14 al 16 de marzo de 2019

Trayectorias: Música entre Latinoamérica y Europa 1970-2000ํำ fue la tercera conferencia internacional organizada por la red de investigadores "Trayectorias". El evento se realizó del 14 al 16 de marzo de 2019 en la Universidad Alberto Hurtado, en Santiago de Chile, con la colaboración de la Academia Chilena de Bellas Artes.

Ya que la conferencia previa se había enfocado en los procesos de circulación y transferencia de músicas (y de sus creadores e intérpretes) en el período de 1945 a 1970, esta vez el énfasis estuvo puesto en las tres décadas siguientes. Las ponencias abordaron aspectos historiográficos, políticos, biográficos y comerciales de estos procesos de circulación entre Latinoamérica y Europa.

La ponencia inaugural, a cargo de Dörte Schmidt (Universität der Künste Berlin), abordó los aspectos políticos de los intercambios musicales entre Latinoamérica y las dos Alemanias de la posguerra, con sus respectivas visiones ideológicas en disputa. En este período se fundan en Alemania Federal instituciones y festivales como el Goethe-Institut, que organizó conciertos y talleres de conjuntos alemanes en Latinoamérica, y las Berliner Festwochen, que dieron espacio a la representación cultural de países no europeos, mientras que los Cursos de Verano de Darmstadt y el Programa para Artistas en Berlín de la DAAD llevaron decenas de compositores latinoamericanos a perfeccionarse a Alemania.

\section{Músicos latinoamericanos en Europa}

La ponencia de Iván César Morales (Universidad de Oviedo) se refirió a los músicos cubanos tras el fin de estos bloques antagonistas, durante el denominado "Período especial". A partir de 1990 se interrumpió el flujo de compositores desde Cuba a los festivales y centros de formación de Berlín Oriental, Praga, Varsovia y Moscú. A la vez, el fin del apoyo soviético sumió al país en una profunda crisis económica, provocando una gran emigración, por diversas vías, de compositores de distintas edades y en distintas etapas de desarrollo. Morales analizó primero la situación privilegiada de Leo Brouwer, un compositor "oficial”, quien mientras se mantenía a la cabeza de la Sinfónica de La Habana, fundó y dirigió la Sinfónica de Córdoba en Andalucía, en cuya programación incorporó música y músicos cubanos. Entre los compositores "no oficiales" se encuentran Keyla Orozco, quien residió en Holanda y también gestionó visitas de intérpretes y compositores cubanos a ese país -antes de su reciente traslado a Estados Unidos-, además de Eduardo Morales-Caso y Ailem

\footnotetext{
1 Sitio de la red de investigadores "Trayectorias": www.trayectorias.org [acceso: 10 de abril de 2020].
} 
Carvajal, emigrados a España e Italia, respectivamente. Mientras Brouwer ocupó un espacio de relativo poder y dominación, sus colegas han debido moverse en dinámicas de apropiación y negociación de espacios subalternos.

Por su parte, Martín Liut (Universidad de Quilmes / Universidad de Buenos Aires), se refirió a los compositores argentinos emigrados a Francia, dando como ejemplo los casos de Horacio Vaggione, Martín Matalon, Luis Naón y Gustavo Beytelmann. Como denominadores comunes, se observó que los compositores permanecieron en Francia tras el restablecimiento de la democracia en Argentina y tendieron a un estilo cosmopolita abstracto, si bien siguieron siendo identificados por sus pares como no franceses tras décadas de residencia en Europa.

Mauricio Gómez Gálvez (Université Paris-Sorbonne) siguió las trayectorias cruzadas de los chilenos Cirilo Vila, Sergio Ortega y Patricio Wang. Vila regresó a Chile en 1970, tras estudiar en Europa con Olivier Messiaen y Max Deutsch. Tras el golpe militar de 1973, Vila decidió quedarse, mientras que Sergio Ortega partió al exilio en Francia. En su larga carrera en la Universidad de Chile, Vila desarrolló su vocación pedagógica, inspirada en el estilo de enseñanza de sus maestros europeos, mientras que Ortega transfirió a Francia la experiencia pedagógica que había iniciado en Chile con alumnos excluidos de la academia, desarrollando un modelo democratizador con músicos amateur o semiamateur. Por su parte, Wang estudió composición con Vila y luego con Louis Andriessen en Holanda, donde reside hasta hoy. No ha ejercido la pedagogía, pero sí ha tenido una estrecha relación con las nuevas generaciones mediante su labor de compositor e intérprete. La estética de Wang, así como las de Vila y Ortega, se ubica entre el universalismo y el nacionalismo, usando en ocasiones instrumentos u otros elementos latinoamericanos, confrontándolos con la tradición europea. En línea con esta temática, la conferencia Trayectorias incluyó un concierto con obras de músicos chilenos emigrados y exiliados en Europa, entre ellos Gabriel Brncic, Leni Alexander, Gustavo Becerra y Patricio Wang.

Mélodie Michel (Universidad de California, Santa Cruz) abordó la situación de los intérpretes latinoamericanos de música antigua. Inicialmente, músicos que emigraban por razones políticas descubrían el movimiento de interpretación históricamente informada de música antigua en Europa. En la década de 1980 muchos pudieron regresar a enseñar a sus países, con lo que hubo un crecimiento exponencial de estudiantes de música antigua en Latinoamérica, varios de estos migraron para perfeccionarse en Europa. Los emigrados se han incorporado con facilidad al entorno cosmopolita del movimiento de la música antigua, al ser muchos de ellos descendientes de migrantes europeos recientes. Sin embargo, siguen siendo identificados más por su origen latinoamericano que por sus habilidades musicales. Un punto de inflexión en los intercambios entre Europa y Latinoamérica en este ámbito fue la celebración del Quinto Centenario en 1992, cuando el sello francés K617 grabó varios discos de música colonial, dirigidos por el argentino Gabriel Garrido, lo que impulsó el cultivo de este repertorio en ambos continentes. Michel señala que, a diferencia de los músicos europeos, los latinoamericanos tendrían más incorporada la transmisión oral y la improvisación en su práctica musical, que son elementos importantes en la música antigua. Los intérpretes de origen latinoamericano estarían usando esto e involucrando más el cuerpo y la sensualidad para producir versiones más exóticas y “auténticas” del repertorio colonial que los distingan de sus pares europeos.

Ricardo Álvarez (Pontificia Universidad Católica de Valparaíso) hizo un recorrido por la historia del jazz en Chile, pasando por la emigración de la mayoría de los músicos de jazz-rock/fusión en los primeros años de la dictadura militar, entre ellos el multiinstrumentista Roberto Lecaros y su hermano, el pianista Mario Lecaros, quien compuso una emblemática Cueca del retorno tras volver de Europa en 1992. Al igual que Lecaros, varios otros músicos de jazz chilenos incorporaron elementos del folclor en su música. Uno de ellos fue el bajista Ernesto Holman, quien, tras una estadía en Nueva York en los años 1980, empezó a recurrir a la tradición musical chilena y mapuche, creando un "etnojazz". La influencia de estos músicos ha sido importante en el desarrollo de un "jazz chileno" por parte de músicos más jóvenes como el pianista Mario Feito (n. 1970) -quien estudió con Cirilo Vila y con el retornado Mario Lecaros-, el guitarrista Raimundo Santander (n. 1983) y el saxofonista Jonathan Gatica (n. 1982), quien desarrolla su estilo como protesta contra la opresión del pueblo mapuche e incorpora otros mensajes de contenido social, antes asociados exclusivamente al folk y al rock.

\section{Músicos y músicas en circulación}

Omar Corrado (Universidad de Buenos Aires) estudió la presencia de profesores europeos en los Cursos Latinoamericanos de Música Contemporánea, en los que participó presencialmente en dos 
ocasiones. Estos quince cursos realizados entre 1971 y 1989 rechazaron la hegemonía del modelo de los Cursos de Darmstadt, adoptando principios como los de ser itinerantes, intensivos y autogestionados, así como tener vínculos con otras disciplinas (del teatro a la filosofía), docentes no pagados y un costo mínimo para los alumnos. Entre los ciento cincuenta profesores participantes, casi cincuenta fueron europeos, incluidos Luigi Nono y Helmut Lachenmann, con predominancia de alemanes. Entre los profesores latinoamericanos, predominaron los argentinos.

El contexto político dado por las dictaduras marcó estos encuentros. Los profesores europeos veían su presencia en los cursos como una forma de resistencia sutil a los regímenes autoritarios. También se planteó la necesidad de apuntalar las identidades culturales como resistencia antiimperialista, y la música contemporánea como espacio de crítica social e institucional, ligada al rescate de la dimensión colectiva (por ejemplo, con el rechazo del virtuosismo individual y la búsqueda de la interpretación en grupo). Estos cursos estimularon el análisis crítico y permitieron la circulación de información en un marco de horizontalidad, sin hegemonías ni imposiciones canónicas de países centrales.

Friederike Merkel (Universität der Künste Berlin) destacó los intercambios culturales relacionados con el Festival Internacional de Música Renacentista y Barroca Americana "Misiones de Chiquitos". E1 festival se inició en 1996 y ofrece una impresionante oferta de conciertos y variados encuentros, incluido un simposio musicológico internacional. Ha atraído un enorme listado de auspiciadores, entre ellos el sello francés K617, el Festival de Ambronay y la Iglesia Luterana, así como embajadas y ministerios de Sudamérica y Europa, junto con cobertura de medios internacionales como la Deutsche Welle, Le Monde y Le Figaro. Todos los conjuntos participantes en el festival deben cumplir con el requisito de interpretar a lo menos una obra del archivo de Chiquitos y Moxos, lo que ha llevado a la difusión de este repertorio colonial, incluso con conciertos y grabaciones por sellos y ensambles europeos. El festival también ha promovido la enseñanza musical en Bolivia, incluyendo, por ejemplo, el inicio de un taller de fabricación de violines. En la sección de preguntas, algunos comentarios vincularon la gestación del festival con el Quinto Centenario, momento en que se disparó el interés por la música colonial, y con el boom de la industria discográfica alrededor de 1990.

Christina Richter-Ibáñez (Universität Tübingen) expuso acerca de la Nueva Canción interpretada en alemán. Representantes del movimiento latinoamericano como Quilapayún, Isabel Parra, Inti-Illimani y Silvio Rodríguez tuvieron destacada presencia en la RDA gracias a iniciativas como el Festival de Canción Política (1970-90). La difusión también fue favorecida por la actividad de sellos discográficos con raíces socialistas, como Pläne (de la RFA), Amiga y Eterna (RDA) o Le Chant du Monde (Francia). El libro Intersongs (1973) contenía partituras y traducciones interlineales, pero además incluía versiones alemanas de canciones como "Comienza la vida nueva" de Advis, "Fusil contra fusil" de Silvio Rodríguez, y "Camilo Torres (Ein Kreuz aus Licht)” de Víctor Jara. Una selección más humanista que política se publicó en el libro Cantaré: Songs aus Lateinamerika (1978). También fue importante la conexión de las iglesias con la teología de la liberación, especialmente con Ernesto Cardenal, cuya poesía fue publicada en la serie Poesiealbum en 1976. Parte de este movimiento cristiano fue el cantautor Gerhard Schöne, quien visitó Nicaragua y grabó un disco con sus impresiones del viaje. Schöne también grabó versiones en alemán de las canciones "Gracias a la vida (Liebes Leben, Danke)" de Violeta Parra y "La maza (Der Hammer)” de Silvio Rodríguez.

Stefano Gavagnin (Universidad de Roma - Sapienza) se refirió a la presencia de la denominada "música andina" en Italia. Esta se hizo conocida mediante la Nueva Canción, especialmente por la presencia del exiliado ensamble Inti-Illimani. Jóvenes conjuntos italianos adoptaron repertorios y prácticas de la Nueva Canción, con énfasis en la música andina. Estos grupos italianos tenían escasas referencias acerca de este repertorio fuera de los discos de Inti-Illimani, y se abocaron a crear una imaginería italiana de los Andes asociada a un discurso sociopolítico y ético en el que también cabían las canciones de protesta de exiliados chilenos, en contraposición con el discurso antropológico exótico de la música andina francesa. A partir de la década de 1980, tuvieron acceso a música "autóctona" de la zona andina, lo que produjo la división de los grupos italianos según su mayor o menor alineación con la Nueva Canción.

La ponencia de Daniel Party (Pontificia Universidad Católica de Chile) abordó a José Luis Perales, cantautor español que fue mucho más apreciado en Latinoamérica que en su propio país, obteniendo su primer Disco de Oro en Argentina. La circulación de su música fue promovida en las décadas de 1970 y 1980 por Hispavox que, tal como otros sellos con base en España, se enfocó en el mercado latinoamericano, mucho más grande que el local. Luis Calvo, chileno residente en Madrid, era director internacional de Hispavox e inició una colaboración con el productor musical de TVN en Chile, Camilo 
Fernández, para promover artistas como Paloma San Basilio, Massiel, Raphael, José Luis Perales y Mari Trini. Llama la atención en Perales que sus canciones de desamor no tengan la agresividad propia de otros autores, ni tampoco muestren interés en las mujeres jóvenes ni en el cuerpo femenino. Revisitar las canciones de Perales en la actual era "\#MeeToo" muestra a un cantautor claramente enclavado en una visión heteronormativa y patriarcal, que enfatiza temas como el matrimonio y los hijos; pero, por otro lado, intenta ponerse en el lugar de las mujeres sin nunca juzgarlas ni maltratarlas.

Matthias Pasdzierny (Universität der Künste Berlin) se refirió a la música tecno como "la otra música chilena del exilio". Una iniciativa importante fue la Eclipse Rave realizada en Arica en 1994, que combinaba un eclipse total de sol, el paisaje del desierto de Atacama y la "futurista" música tecno. El evento fue posible gracias a los DJ Martin Schopf y Ricardo Villalobos, ambos nacidos en Chile y residentes desde su infancia en Alemania debido al exilio de sus padres. Ellos convocaron a músicos alemanes para llevar a Chile algo de la actividad del masivo movimiento tecno que crecía en el país europeo. La realización del evento tuvo serios inconvenientes prácticos y convocó a escaso público, además de chocar con malentendidos culturales debido a que la música tecno era demasiado desconocida para el público local. Sin embargo, ha adquirido un estatus mítico como supuesto punto de partida en el intercambio cultural tecno entre Alemania y Chile, en el que ha tenido un rol central la segunda generación de exiliados chilenos, representada por Villalobos, Schopf y la hermana de este, Chica Paula. Con ellos, el tecno se ha instalado como "la otra música del exilio", en contraposición con la Nueva Canción Chilena y la música andina.

Dulce María Dalbosco (CONICET Argentina) reflexionó acerca de las convergencias entre las poéticas del tango y el fado. Dalbosco tomó como punto de partida el trabajo de la cantante de tangos Karina Beorlegui, quien descubrió el fado a fines de los años 1990 y se convirtió en embajadora del género en Argentina. Beorlegui afirma que las afinidades entre ambos géneros se deben a su origen portuario: "los puertos son lugares de paso, de desarraigo, pero también de encuentro, mixtura e identidad”, señala ella. El fado está presente en Argentina desde hace un siglo; de hecho, Gardel grabó cuatro fados. Según Vera Sepúlveda, este género habría ejercido su influencia en la formación de géneros portuarios de América del Sur: el tango rioplatense, la ranchera de Veracruz, el valsecito criollo de El Callao de Lima y el valsecito porteño de Valparaíso. Las afinidades poéticas entre el tango y el fado pueden observarse, por ejemplo, en las relaciones intersubjetivas que describen, marcadas por la frustración y la inestabilidad. Más confiables aparecen los objetos, que adquieren características humanas, como el "bandoneón arrabalero" del tango o el chal (xaile) del fado. Ambos géneros también recurren a la topofilia, celebrando a los barrios de sus ciudades de origen.

\section{Músicos europeos en Latinoamérica}

Varios casos de músicos que migraron desde Europa constituyeron un último bloque de ponencias enfocado en el período anterior a 1970, que fuera el eje de las dos primeras conferencias de Trayectorias.

Fernando Beyer (Universität Salzburg) se refirió a Hanns Eisler y su breve estadía en México, en 1939-40, un período tradicionalmente considerado como poco importante. Eisler, rechazado en Estados Unidos por su filiación comunista, se refugió en México hacia el final del gobierno de Lázaro Cárdenas, quien acogió también a Leon Trotsky y a numerosos exiliados republicanos españoles, así como a austriacos que escapaban del nazismo. A su llegada a México, un periódico recibió a Eisler como "eficaz colaborador del pueblo mexicano", mientras que se creó una cátedra para él en el Conservatorio Nacional. Su ingreso a México parece haber sido apoyado por la Confederación de Trabajadores de México y el compositor José Pomar, de militancia comunista. Pese a estas conexiones, Eisler guardó estricto silencio político en México y, al ser interrogado por las autoridades de Estados Unidos al inicio de la Guerra Fría, insistió en que su único interés era el musical. En lo político, Eisler parece haberse visto obligado a transar en pos de su supervivencia, lo que viene a cuestionar las imágenes heroicas de los exiliados.

Adriana Carolina Correa (Universidad Nacional de Colombia) se refirió a otro migrante europeo, el belga Léon J. Simar (1909-1983). Tras permanecer en Lieja bajo la ocupación nazi, el compositor se trasladó a Cali, Colombia, en 1949, para evitar la persecución contra los sospechosos de colaborar con los alemanes. En Colombia se dedicó mayormente a realizar arreglos y contribuyó a la consolidación del sistema de educación y profesionalización musical del país. Se integró al Conservatorio de Cali y fundó la Escuela de Música de la Universidad del Valle. Entre otros aportes, creó un método para la enseñanza musical basado en Hindemith, el programa didáctico radial "Hablemos de música" y la 
revista musical Euterpe. Sin embargo, queda la interrogante de por qué su vasta producción (ciento cinco obras originales) permanece sin ser reconocida en el contexto colombiano, pese a haber ganado importantes premios en Europa antes de su migración.

Diego Alonso (Universidad Humboldt Berlin) se refirió al musicólogo Otto Mayer-Serra, quien vivió dos exilios. Nacido en Berlín en 1904 en una familia judía burguesa interesada en las artes, escribió acerca del aporte de la radio a la democratización de la música y llamó a componer específicamente para dicho medio y en relación con los intereses de la clase proletaria. En 1933, al desbaratarse la red de intelectuales judíos de izquierda, se trasladó a Barcelona, sin tener conexiones allí ni conocer el idioma. Pese a ello, fue contratado por el periódico Mirador y se convirtió en un escritor frenético desde entonces. En Alemania Mayer-Serra había participado en discusiones acerca de un nuevo enfoque marxista acerca de la historia y composición musicales, que lo llevaron a ser un pionero de la sociología musical. En 1938 publicó en España En torno a una sociología de la música, donde aborda la relación entre el capitalismo y la historia de música, criticando la comercialización ejemplificada en el virtuoso que busca conquistar al público. Para Mayer-Serra la Nueva Música debía subvertir este orden burgués y los compositores debían ser portavoces de un nuevo orden social. Como propagandista musical del lado republicano en la Guerra Civil, Mayer-Serra debió exiliarse nuevamente, esta vez en México, hasta su muerte en 1986.

Luis Merino (Universidad de Chile / Academia Chilena de Bellas Artes) se refirió a otro musicólogo que llegó exiliado a Latinoamérica desde España. Vicente Salas Viu realizó una contribución fundacional a la investigación musical en Chile entre 1939 y 1953, siempre en estrecha colaboración con Domingo Santa Cruz. Ambos trabajaron en la formación del Instituto de Extensión Musical y en la programación de la Orquesta Sinfónica de Chile, inclinándose más por las obras de Stravinski que por la Segunda Escuela de Viena. Salas Viu dirigió el Instituto de Investigaciones Musicales y la Revista Musical Chilena, plasmándole el perfil que mantiene hasta hoy. Si bien rechazó el nacionalismo (entendido como el uso de la música vernácula), hubo en la revista una mirada americanista, reflejada, por ejemplo, en los ensayos de Adolfo Salazar y la importancia que se dio a Heitor Villa-Lobos. Con un rol tan importante en la creación de la institucionalidad musical chilena, puede afirmarse que, en su libro La creación musical en Chile (1900-51), Salas Viu se refiere a algo que él mismo contribuyó a crear.

\section{Conclusión}

La conferencia terminó con una discusión en la que se identificaron tendencias generales que emergieron de los estudios presentados y en las que valdría la pena seguir profundizando. En relación con las migraciones de compositores e intérpretes surgen diversas problemáticas acerca de la integración de estos músicos a nuevos contextos culturales, con la construcción de identidades fragmentadas teñidas por la otredad y, a veces, la autoexotización ante la cultura imperante. En las migraciones transatlánticas de músicos también se observó el accionar de redes de solidaridad sostenidas por instituciones de la izquierda política que facilitaron el desplazamiento e integración de los músicos europeos y latinoamericanos en diversos países y épocas. Componentes políticos e ideológicos de la rivalidad entre las dos superpotencias de la Guerra Fría también están presentes en muchas ponencias que aluden al contexto de las dictaduras latinoamericanas y a las relaciones entre Latinoamérica y las dos Alemanias.

Esta conferencia permitió apreciar variados abordajes acerca de la migración de músicos, así como de la circulación de gran diversidad de músicas populares y doctas entre Latinoamérica y Europa. Revela un panorama muy estimulante en el que queda mucho por explorar, por ejemplo, en relación con el rol de las ideologías políticas, los medios de comunicación y el mercado discográfico, así como las problemáticas de la construcción de identidad de los músicos, pero también de sus públicos, y su entrecruzamiento con las problemáticas de género. 